\title{
Rapid Clearance of Surfactant-Associated Palmitic Acid from the Lungs of Developing and Adult Animals
}

\author{
BANNIE TABOR, MACHIKO IKEGAMI, TAKAKO YAMADA, AND ALAN JOBE \\ Departments of Obstetrics and Pediatrics, Harbor-UCLA Medical School, UCLA School of Medicine, Torrance, \\ California 90509
}

\begin{abstract}
Palmitic acid is a minor component of natural surfactant and has been used to modify lipid extracts of natural surfactants to optimize their in vitro surface properties. The metabolic fate of palmitic acid in surfactant is unknown. The clearance of surfactant-associated radiolabeled palmitic acid after intratracheal administration was investigated with trace doses of surfactant in the adult rabbit and with trace and treatment doses in the 28-d fetal rabbit and the 132-d fetal sheep. Palmitic acid was cleared rapidly from the airways, with less than $2 \%$ of the radiolabel recovered as free palmitic acid in the alveolar wash by $1 \mathrm{~h}$ in all models. Recovery as free palmitic acid in the total lung at $2 \mathrm{~h}$ was $2 \%$ in the adult rabbit and $3 \%$ both doses in the preterm rabbit. In the preterm sheep, the recovery as free palmitic acid in the total lung was approximately $2 \%$ of the trace dose and $1 \%$ of the treatment dose by $5 \mathrm{~h}$. Between 5 and $15 \%$ of the instilled palmitic acid was used as substrate for phospholipid synthesis by the lung in the different models. About $30 \%$ of the palmitate derived label was recovered in lipid extracts of liver $30 \mathrm{~min}$ after tracheal instillation of labeled surfactant in adult rabbits, whereas only $5-10 \%$ of the palmitate derived label was found in liver lipids in the preterm animals. In contrast to palmitic acid, radiolabeled triglyceride was cleared much more slowly from the airspaces and lungs of preterm sheep. Inasmuch as large amounts of palmitic acid are cleared rapidly from airspaces and lung tissue, it will not have a prolonged effect on the surface properties of surfactant but it may serve as a precursor for lung lipid metabolism. (Pediatr Res 27: 268-273, 1990)
\end{abstract}

\section{Abbreviations}

DPPC, dipalmitoylphosphatidylcholine SPC, saturated phosphatidylcholine RDS, respiratory distress syndrome

Surfactant is a complex lipoprotein mixture, composed of about $85 \%$ phospholipid, $10 \%$ protein, and $5 \%$ neutral lipids and cholesterol $(1,2)$. The largest single component is DPPC, comprising about $50 \%$ by wt of total surfactant. Given the high DPPC content and the esterified palmitate content in other phospholipids and triglycerides, about $70 \%$ of the esterified fatty acid in surfactant is palmitate (3). Free fatty acids, which are

Received July 31, 1989; accepted October 13, 1989.

Correspondence Bannie Tabor, M.D., Harbor-UCLA Medical Center, Department of Pediatrics, Division of Neonatology A-17 Annex, 1000 W. Carson Street, Torrance, CA 90509

Supported by Grant HD-12714 from the Department of Health and Human Services, Child Health and Development and by Ross Laboratories. primarily palmitic acid, represent less than $1 \%$ of surfactant (4). Despite the low free palmitic acid content of natural surfactant, $7 \%$ by wt palmitic acid and $3 \%$ by wt tripalmitin were added to a surfactant prepared by lipid solvent extraction of beef lung to favorably alter in vitro surface properties (5). This surfactant, survanta, improved the respiratory failure of infants with RDS (5-8). Palmitic acid also was added to a number of phospholipid and surfactant protein mixtures used to study the function of the surfactant proteins $(9-11)$. Trace amounts of palmitic acid when given into the airways of healthy animals became incorporated into surfactant phospholipids and thus palmitic acid served as a precursor for surfactant (12). Although various aspects of the clearance of the large amounts of phospholipids and cholesterol instilled into the lungs have been described (13-15), the fate of trace or large amounts of palmitic acid remains unknown. Inasmuch as surfactants containing large amounts of palmitate are used clinically, we studied the clearance of intratracheally instilled palmitic acid, a component that plays a role of considerable importance to the in vitro surface properties of these surfactant preparations. Three different animal models were used to evaluate any differences in the clearance between species or between age groups within the same species.

\section{MATERIALS AND METHODS}

Adult rabbits. The clearance of the $\left[{ }^{14} \mathrm{C}\right]$ palmitic acid and $\left[{ }^{3} \mathrm{H}\right]$ palmitate labeled DPPC associated with natural rabbit surfactant were compared. $\left[{ }^{14} \mathrm{C}\right]$ palmitic acid and $\left[{ }^{3} \mathrm{H}\right] \mathrm{DPPC}$ were dissolved in chloroform, dried in a rotary flask evaporator on a roundbottom glass flask, and resuspended to form multilamellar vesicles in $3 \mathrm{~mL} 0.45 \% \mathrm{NaCl}$ with shaking, using glass beads. Unlabeled rabbit surfactant isolated as described previously and containing $\sim 60$ - mg total lipid was added to this suspension (13). The mixture was centrifuged at $27000 \times g$ for $20 \mathrm{~min}$. The pellet was resuspended in $120 \mathrm{~mL}$ of $0.45 \% \mathrm{NaCl}$ to yield a final suspension containing $0.5 \mathrm{mg}$ total lipid $/ \mathrm{mL}, \sim 1 \mu \mathrm{Ci}\left[{ }^{3} \mathrm{H}\right]$ $\mathrm{DPPC} / \mathrm{mL}$, and $\sim 2 \mu \mathrm{Ci}\left[{ }^{14} \mathrm{C}\right]$ palmitic acid $/ \mathrm{mL}$, which was used for the tracheal injections.

Twenty-five New Zealand White rabbits weighing $1.08 \pm 0.03$ $\mathrm{kg}$ were anesthetized with ether and a bite block was inserted between the incisors. A flexible bronchoscope modified by exteriorizing the procedure channel $8 \mathrm{~cm}$ from the tip was used to visualize the vocal cords. Under direct visualization, a $2-\mathrm{mm}$ diameter catheter was inserted through the cords to about the level of the carina, the chest of the animal was manually compressed, and $4 \mathrm{~mL}$ of the labeled surfactant suspension were injected as compression was released (13). Retention of the injected suspension within the lungs was visually verified.

The animals were killed with i.v. pentobarbital in groups of five at $5 \mathrm{~min}, 30 \mathrm{~min}, 2,4$, and $16 \mathrm{~h}$ after tracheal injection. The abdominal aorta of each animal was cut, the chest and neck were 
opened, and the trachea was isolated. A plastic cannula was tied into the trachea and the lungs were thoroughly lavaged five times with chilled normal saline (13). The alveolar washes from each animal were pooled and the volume recorded. The lungs were removed, homogenized in normal saline, and the volume recorded. The liver was removed and weighed. A small portion was weighed, homogenized in normal saline with a Teckmar (Cincinnati, $\mathrm{OH}$ ) homogenizer, and the volume recorded.

Preterm ventilated rabbits. The clearance of labeled palmitic acid from treatment and trace doses of survanta was investigated in premature rabbits. Survanta is a surfactant made by lipid solvent extraction of calf lung minces and supplemented to contain by wt $48 \%$ DPPC, $7-8 \%$ palmitic acid, and $7 \%$ tripalmitin $(5,16)$. Eight $\mathrm{mL}$ of survanta $(25 \mathrm{mg}$ lipid $/ \mathrm{mL})$ were extracted with chloroform:methanol $(2: 1)$, after which $4 \mathrm{mCi}$ $\left[{ }^{3} \mathrm{H}\right]$ palmitic acid was added to the lipid extract and multilamellar liposomes were prepared as above. The final suspension contained $150 \mu \mathrm{Ci}\left[{ }^{3} \mathrm{H}\right.$ ]palmitic acid/mL and $\sim 12.5 \mathrm{mg}$ total surfactant lipid/mL. A second labeled survanta was prepared by Abbott laboratories by adding $\left[{ }^{14} \mathrm{C}\right]$ palmitic acid during formulation. This surfactant contained $25 \mu \mathrm{Ci}$ of $\left[{ }^{14} \mathrm{C}\right]$ palmitic acid/mL and $25 \mathrm{mg}$ total lipid/mL. Clearance of the two isotopes were compared to validate our method of labeling the surfactant. These two labeled surfactants were mixed to prepare trace and treatment doses of the surfactant.

Time bred New Zealand White rabbits were delivered by cesarean section using spinal anesthesia on d 28 of gestation. The newborn rabbits, weighing $38.4 \pm 0.7 \mathrm{~g}$, were given $10 \mathrm{mg} /$ $\mathrm{kg}$ ketamine and $0.1 \mathrm{mg} / \mathrm{kg}$ acepromazine by i.p. injection. The trachea of each rabbit was isolated and a tube made from a $17-\mathrm{g}$ needle was tied into the trachea. The chest was compressed and released as $0.2 \mathrm{~mL}$ of either the treatment or trace surfactant suspensions were injected intratracheally (17). Rabbits given the treatment dose received $100 \mathrm{mg} \mathrm{lipid} / \mathrm{kg}$ body wt, $2.0 \mu \mathrm{Ci}\left[{ }^{3} \mathrm{H}\right]$ palmitic acid, and $0.5 \mu \mathrm{Ci}\left[{ }^{14} \mathrm{C}\right]$ palmitic acid. The trace dose of surfactant contained $4 \mathrm{mg}$ lipid/kg body wt, $0.6 \mu \mathrm{Ci}\left[{ }^{3} \mathrm{H}\right]$ palmitic acid and $0.1 \mu \mathrm{Ci}\left[{ }^{14} \mathrm{C}\right]$ palmitic acid. Approximately five breaths were given with an anesthesia bag and manometer with $100 \%$ oxygen to initiate ventilation, after which the rabbits were transferred to a ventilator plethysmography system temperature controlled at $37^{\circ} \mathrm{C}(17)$. Ventilation was with $100 \%$ oxygen at a rate of 40 breaths $/ \mathrm{min}$, an inspiratory time of $0.7 \mathrm{~s}$, a peak inspiratory pressure of $35 \mathrm{~cm} \mathrm{H}_{2} \mathrm{O}$, and an end expiratory pressure of 0 . The tidal volume was measured frequently with a pneumotachometer to maintain a tidal volume of $10-12 \mathrm{~mL} / \mathrm{kg}$ by adjusting the peak inspiratory pressure requirement for each rabbit (18).

Five rabbits from each treatment group were killed with intrathecal lidocaine after $10 \mathrm{~min}, 30 \mathrm{~min}, 1 \mathrm{~h}$, and $2 \mathrm{~h}$ of ventilation. Blood was drawn from the heart immediately after death, and the plasma was separated and frozen. The lungs then were thoroughly lavaged five times with $0.9 \% \mathrm{NaCl}$ and the vol was recorded (18). The lungs were removed, homogenized in normal saline, and the volume recorded. In a similar fashion the liver was removed, weighed, homogenized in normal saline, and the volume recorded.

Preterm ventilated lambs. The clearance of palmitic acid and tripalmitin from treatment doses (100 mg total lipid $/ \mathrm{kg}$ ) or trace doses $(<5 \mathrm{mg}$ total lipid $/ \mathrm{kg}$ ) of survanta was investigated in preterm sheep. A [ $\left.{ }^{3} \mathrm{H}\right]$ palmitic acid labeled surfactant suspension was prepared as described above. The final suspension contained $150 \mu \mathrm{Ci}\left[{ }^{3} \mathrm{H}\right]$ palmitic acid/mL and $12.5 \mathrm{mg}$ total lipid/mL. A second surfactant suspension containing $16 \mu \mathrm{Ci}\left[{ }^{14} \mathrm{C}\right]$ palmitate labeled tripalmitin/mL and $12.5 \mathrm{mg}$ total lipid/mL was similarly prepared. Each lamb was randomized at the time of delivery to receive an individually prepared dose of either treatment or trace doses of the labeled surfactant that contained $30 \mu \mathrm{Ci}\left[{ }^{3} \mathrm{H}\right]$ palmitic acid and $1.6 \mu \mathrm{Ci}\left[{ }^{14} \mathrm{C}\right]$ tripalmitin. The treatment dose was prepared by mixing the two labeled surfactant suspensions with unlabeled survanta in $0.45 \% \mathrm{NaCl}$ to provide $100 \mathrm{mg}$ total lipid/ $\mathrm{kg}$ body wt in a $4 \mathrm{~mL} / \mathrm{kg}$ surfactant suspension. The trace dose was prepared by mixing the two labeled suspensions with approximately $8 \mathrm{~mL}$ of the lamb's own fetal lung fluid.

Ewes carrying twins or triplets at $132 \mathrm{~d}$ gestational age were preanesthetized with $1 \mathrm{~g}$ ketamine and $2.4 \mathrm{mg}$ atropine given by intramuscular injection. The ewes were then given spinal-epidural anesthesia using $8 \mathrm{~mL}$ of a 1:1 mixture of $2 \%$ lidocaine and $0.5 \%$ bupivicaine. Each fetal head was subsequently delivered through a midline abdominal and uterine incision. The snout of each fetus was wrapped with saline-soaked gauze to prevent breathing. Each lamb received an estimated dose of 10 $\mathrm{mg} / \mathrm{kg}$ ketamine and $0.1 \mathrm{mg} / \mathrm{kg}$ acepromazine by intramuscular injection. Local anesthesia with lidocaine was given to the skin and s.c. tissues over the trachea and a tracheostomy was performed. A cross-clamped endotracheal tube was tied into the trachea and 5-10 mL of fetal lung fluid were aspirated. The lamb was delivered and weighed with maintenance of umbilical perfusion. The calculated dose of the labeled surfactant was given to the lamb via the endotracheal tube (15). A sample for blood gas and $\mathrm{pH}$ analysis was drawn from the cord, the cord was cut, and the animal transferred to a radiant warming bed for ventilation with a Sechrist (Anahiem, CA) infant ventilator. The initial settings were rate: 30 breaths/min; inspiratory time: $1 \mathrm{~s}$; positive end expiratory pressure: $2 \mathrm{~cm} \mathrm{H}_{2} \mathrm{O}$; peak inspiratory pressure: $35 \mathrm{~cm} \mathrm{H}_{2} \mathrm{O}$; and $\mathrm{FiO} 2: 50 \%$. Subsequently only the peak inspiratory pressures and the $\mathrm{PO}_{2}$ were changed to regulate the $\mathrm{PCO}_{2}$ and the $\mathrm{PO}_{2}$ values (19).

Immediately after delivery and the start of ventilation, each animal was dried and a 5 Fr catheter was passed via an umbilical artery into the distal aorta. Blood was drawn at $10,30,60$, and $120 \mathrm{~min}$ for measurement of the radiolabels in plasma. The animals received supplemental ketamine:acepromazine every 3 to $4 \mathrm{~h}$. In addition, the $8-\mathrm{h}$ time group received $2 \mathrm{mg} / \mathrm{kg}$ gentamicin. The arterial catheter was maintained open with a continuous infusion of $5 \%$ glucose in water given at a rate of $4 \mathrm{~mL} /$ $\mathrm{kg} \cdot \mathrm{h}$. Blood pressures, heart rates, and temperatures were monitored and arterial $\mathrm{pH}, \mathrm{PO}_{2}$ and $\mathrm{PCO}_{2}$ values were measured hourly until the animals were killed by intravascular pentobarbital injection and exsanguinated in groups of five to six lambs at 1,3 , 5 , and $8 \mathrm{~h}$ after delivery.

The lungs were carefully removed from the chest, weighed, and connected to a $0.9 \%$ saline-filled reservoir that was $25 \mathrm{~cm}$ above the level of the hilum. The cold saline was allowed to flow into the lungs for about 1 min until the lungs were visibly well distended, but the lungs were not filled to the static pressure of $25 \mathrm{~cm} \mathrm{H}_{2} \mathrm{O}(15)$. The saline volume was withdrawn with a syringe and this procedure was repeated five times. The alveolar washes were pooled and the volume was measured. The lungs were then chopped with scissors, homogenized in normal saline, and the lung homogenate volume recorded. The liver was removed and weighed. A portion of the liver was removed, weighed, and homogenized in normal saline.

Processing of samples. Lipid extracts of the surfactant suspensions used for the treatments, alveolar washes, lung and liver homogenates, and plasma were prepared using chloroform: methanol (2:1) (20). In preliminary experiments, this extraction procedure recovered $88.0 \pm 3.6 \%$ of radiolabeled palmitic acid. Phosphatidylcholine was isolated from the lipid extracts using one-dimensional chromatography on silica gel plates with chloroform:methanol:acetic acid:water (16:6:2:1) as the solvent. Neutral lipids were separated on silica gel plates using a hexane:ether:formic acid (40:10:1) solvent (14). The neutral lipid and phospholipid spots were visualized with iodine vapor. SPC was isolated by alumina column chromatography after osmium tetroxide treatment of the lipid extracts (21). All radioactivity determinations were with Scintiverse (Fisher Scientific, Pittsburgh, PA) with quench and cross-channel correction for the double label experiments. The results are presented as mean \pm $\mathrm{SE}$ percent recoveries relative to triplicate measurements of aliquots of the surfactant suspensions processed identically to the samples. Calculations of recoveries in blood were made 
assuming a hematocrit of $40 \%$ and a blood vol of $100 \mathrm{~mL} / \mathrm{kg}$. Statistical analysis was performed using unpaired Student's $t$ tests and one-way analysis of variance with Student-Newman-Keuls test. Significance was accepted at $p<0.05$.

\section{RESULTS}

Adult rabbits. Trace amounts of palmitic acid were cleared very rapidly from the airspace into the lung, and subsequently removed from the lung itself (Fig. 1). Five min after intratracheal injection, only $6.1 \pm 0.9 \%$ of the palmitic acid was recovered from the airspaces as free palmitic acid. By $30 \mathrm{~min}$, only $0.9 \pm$ $0.2 \%$ was recovered, with negligible amounts thereafter. The clearance from the lung was similar but not quite as rapid. At 5 min, $17.4 \pm 2.3 \%$ was recovered as free palmitic acid in the total lung (the sum of recoveries in the alveolar wash plus lung homogenate). Palmitic acid continued to leave the lung tissue, so that by $2 \mathrm{~h}$ only $1.6 \pm 0.3 \%$ was found in the total lung. This declined to less than $1 \%$ by $16 \mathrm{~h}$. A portion of the palmitic acid was used as a substrate for the synthesis of SPC, as evidenced by the recovery of $5-10 \%$ of the palmitate label in total lung SPC. The largest fraction was found in the lipid extracts of liver. Almost $30 \%$ of the palmitate derived label was found in the liver at $30 \mathrm{~min}$, with the percent recovery that subsequently decreased linearly. At $30 \mathrm{~min}, 50.5 \pm 2.8 \%$ of the label in the liver was in neutral lipids (triacyl- and diacylglycerols, cholesterol palmitate, and free palmitic acid), $16.0 \pm 2.1 \%$ in phosphatidylcholine, and the remainder in other phospholipids.

Labeled DPPC was previously found to be cleared at a rate of about $1.8 \% / \mathrm{h}$ from the alveolar washes of adult rabbits (13). In this experiment the clearance of DPPC was compared to that of the labeled palmitic acid. The recovery ratio of DPPC to palmitic acid in the alveolar wash was $7: 1$ at $5 \mathrm{~min}, 40: 1$ at $30 \mathrm{~min}$, and $>100: 1$ by $2 \mathrm{~h}$, indicating a much more rapid clearance of palmitic acid $(p<0.01)$.

Preterm ventilated rabbits. Palmitic acid was cleared rapidly from the airspaces as indicated by the low percentage recovery of radioactivity in the alveolar wash lipid extracts (Fig. $2 A$ ). At $10 \mathrm{~min}, 11.3 \pm 1.7 \%$ of the labeled palmitic acid from the treatment dose was recovered, and this recovery continued to fall until only $1.0 \pm 0.2 \%$ was recovered at $2 \mathrm{~h}$. The label recovered in the alveolar wash was almost entirely recovered as palmitic acid indicating no appreciable incorporation of palmitate into other lipids and subsequent secretion into the alveolus by $2 \mathrm{~h}$.

The clearance of the palmitic acid in the trace dose of surfactant was significantly more rapid than for the treatment dose $(p$ $<0.01$ ). At $10 \mathrm{~min}$ only $1.7 \pm 0.1 \%$ of the isotope was recovered in the lipid extract, with less than $1 \%$ found at the subsequent time points. The individual components of the lipid extracts

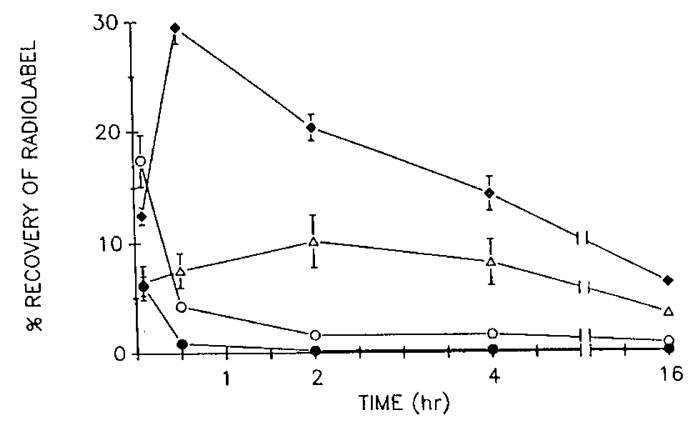

Fig. 1. Recovery of surfactant-associated labeled palmitic acid given by intratrachel injection to adult rabbits. Error bars for SEM not shown fall within the symbols. The recovery of $\left[{ }^{14} \mathrm{C}\right]$ palmitate is given as: 1 ) palmitic acid in the alveolar wash $(\bullet)$;2) palmitic acid in the total lung (alveolar wash + lung homogenate) $(O) ; 3)$ saturated phosphatidylcholine in the total lung $(\triangle)$; and 4 ) total lipid extract in the liver $(\diamond)$.
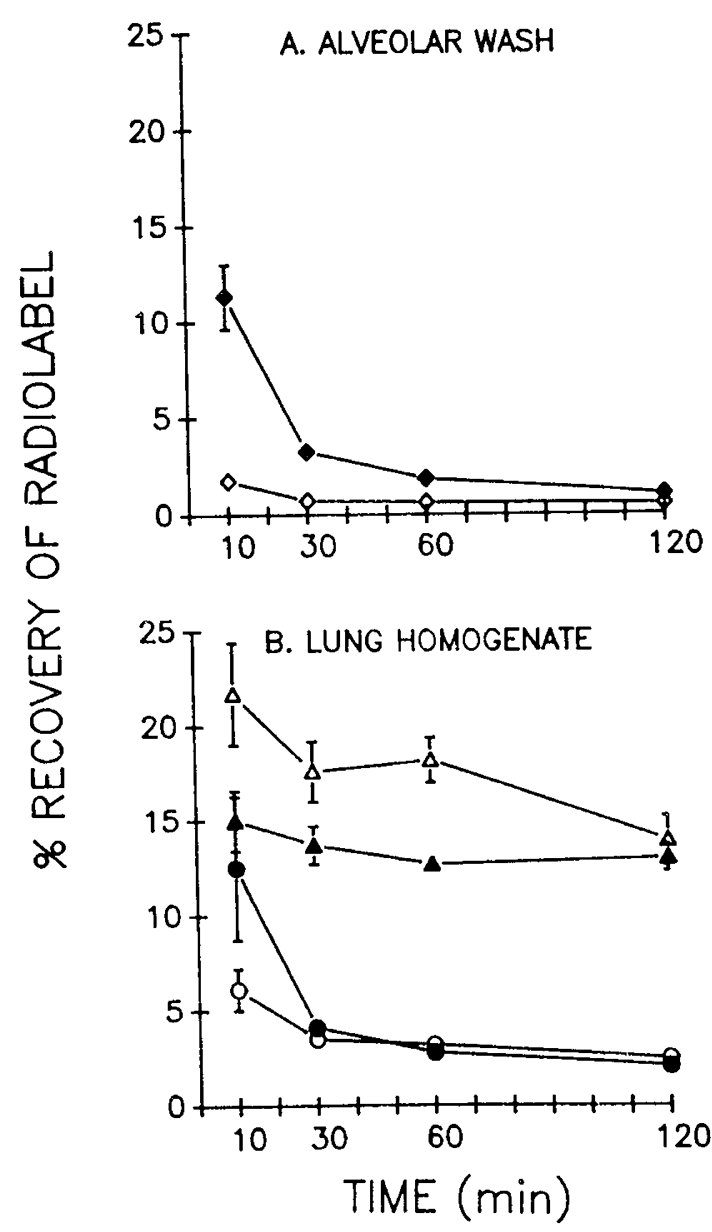

Fig. 2. Recovery of surfactant-associated labeled palmitic acid given by intratracheal injection to 28 -d rabbits. Error bars not shown fall within the symbols. $A$, the recovery of $\left[{ }^{3} \mathrm{H}\right]$ palmitate in total lipid extract from the alveolar wash is given for treatment $(\diamond)$ or trace $(\diamond)$ doses of surfactant. The clearance is significantly more rapid in the trace dose at all time points $(p<0.01) . B$, the recovery of $\left[{ }^{3} \mathrm{H}\right]$ palmitate in the lung homogenate is given as palmitic acid in the treatment $(\bullet)$ and trace $(O)$ doses of surfactant or in phosholipid in the treatment $(\mathbf{\Lambda})$ and trace $(\triangle)$ doses.

from the trace dose were not examined because the overall recovery in the lipid extracts was so small.

The recovery of palmitic acid in the lung tissue was comparable in the two dose groups, with less than $5 \%$ recovered after $30 \mathrm{~min}$ (Fig. $2 B$ ). Most of the recovered label was found in phospholipids in the lipid extracts, again with similar relative recoveries in the two dosage groups. The palmitic acid derived radioactivity was lost rapidly from the total lung. Only $42.8 \pm 6.5 \%$ of the injected radiolabel was recovered in the lipid extract from the total lung at $10 \mathrm{~min}$. This declined to $22.7 \pm 1.3 \%$ at $30 \mathrm{~min}$. By $10 \mathrm{~min}$, $8.5 \pm 2.1 \%$ of the palmitate label was found in the lipid extract from the liver. This increased to $14.2 \pm 1.4 \%$ at $30 \mathrm{~min}$ and then remained fairly constant at $13.4 \pm 0.3 \%$ and $11.8 \pm 1.1 \%$ at 1 and $2 \mathrm{~h}$, respectively. Less than $1 \%$ of the radiolabel was found in plasma at any time. The clearance of $\left[{ }^{3} \mathrm{H}\right]$ palmitic acid, which was added to the surfactant suspension as multilamellar liposomes, was the same as that of the $\left[{ }^{14} \mathrm{C}\right]$ palmitic acid added during surfactant formulation.

Preterm ventilated sheep. The preterm sheep given treatment doses of surfactant were successfully ventilated over the course of the experiment, with a mean $\mathrm{pH} 7.34 \pm 0.03, \mathrm{PO}_{2} 79 \pm 37$, and $\mathrm{PCO}_{2} 40 \pm 5$ at $8 \mathrm{~h}$. In contrast, the animals that received the trace dose had severe respiratory failure at $5 \mathrm{~h}$, as evidenced by a mean pH $7.14 \pm 0.15, \mathrm{PO}_{2} 36 \pm 8$, and $\mathrm{PCO}_{2} 90 \pm 39$ despite high ventilatory pressures of $38.3 \pm 0.8 \mathrm{~cm} \mathrm{H}_{2} \mathrm{O}$, and were not 
studied beyond the 5-h time point. Palmitic acid was cleared rapidly from the airspaces in both trace and treatment dose groups (Fig. $3 A$ and $B$ ). The recovery of the radiolabel in the alveolar wash lipid extracts at $1 \mathrm{~h}$ was $1.7 \pm 0.5 \%$ in the treatment dose and $1.5 \pm 0.1 \%$ in the trace dose groups. Less than $1 \%$ was recovered at the later time points for both doses. Inasmuch as the recovery was so small, the percent recovery in the individual lipid fractions was not measured. The percent recovery of the radiolabel in lipid extracts of lung tissue was similar for the two dosage groups, as was the distribution of the labeled palmitate within the lipid components. At $5 \mathrm{~h}$ the ratios for label recovery in phospholipid:palmitic acid:triglyceride were 77:14:9 for the treatment dose and 74:15:11 for the trace dose. Approximately $5 \%$ of the administered palmitate was recovered from the liver homogenate lipid extracts at all time points in both groups. At 5 $\mathrm{h}$ the ratio of phospholipid:palmitic acid in the liver was $5: 1$.

The percent recovery of the labeled palmitate in SPC in the lung homogenate was measured. For the treatment group, the recovery in SPC was $4.1 \pm 1.1 \%$ at $1 \mathrm{~h}, 2.0 \pm 0.5 \%$ at $3 \mathrm{~h}, 1.3$ $\pm 0.5 \%$ at $5 \mathrm{~h}$, and $1.8 \pm 0.3 \%$ at $8 \mathrm{~h}$. For the trace group, 6.6 $\pm 0.8 \%$ was recovered at $1 \mathrm{~h}, 3.7 \pm 0.7 \%$ at $3 \mathrm{~h}$, and $3.1 \pm 0.5$ at $5 \mathrm{~h}$. This represented approximately $25 \%$ of the recovery of the label in the lipid extracts for both doses at each time point. Although the percent recovery in SPC was higher at $1 \mathrm{~h}$ than at the subsequent time points for both the treatment and trace doses $(p<0.05)$, there were no further significant time-dependent decreases.

The percent recovery of radiolabel in the plasma lipids indicated rapid transport of palmitic acid out of the lung. Assuming

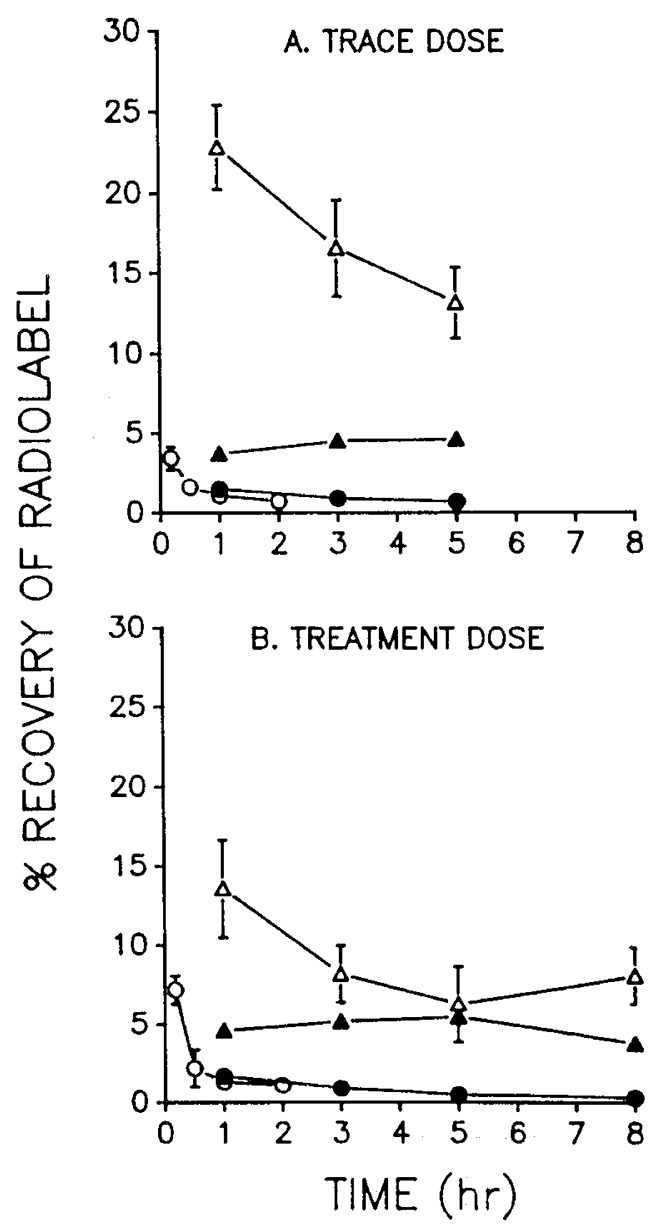

Fig. 3. Recovery of surfactant-associated labeled palmitic acid given by intratracheal injection to $132-\mathrm{d}$ sheep. Error bars not shown fall within the symbols. The recovery of $\left[{ }^{3} \mathrm{H}\right]$ palmitate in the lipid extracts of total plasma vol $(O)$, alveolar wash $(\bullet)$, lung homogenate $(\triangle)$, and the liver $(\mathbf{A})$ are given for the trace $(A)$ and treatment $(B)$ doses of surfactant. an average blood volume of $100 \mathrm{~mL} / \mathrm{kg}$ body wt in these animals with an average body wt of $2.8 \mathrm{~kg}$, approximately $7 \%$ of the palmitate was found in the blood at $10 \mathrm{~min}$ and $2.5 \%$ at $30 \mathrm{~min}$. The percent recovery in blood of the trace dose group was $3.5 \%$ at $10 \mathrm{~min}$, a value significantly less than that calculated for the treatment dose group $(p<0.01)$.

The clearance of $\left[{ }^{14} \mathrm{C}\right]$ tripalmitin was markedly different than that of palmitic acid (Fig. 4). The tripalmitin was slowly cleared from the airways in both surfactant dosage groups. By $5 \mathrm{~h}, 22.5$ $\pm 8.4 \%$ of the treatment dose and $5.7 \pm 1.1 \%$ of the trace dose was recovered from the alveolar wash lipid extracts, with total lung recoveries of $77.8 \pm 5.7$ and $44.7 \pm 5.7 \%$, respectively. The recovery of the treatment dose from both the alveolar wash and total lung lipid extracts at 3 and $5 \mathrm{~h}$ were significantly greater than that of the trace dose $(p<0.05)$. The recovery ratio of the radiolabel as phospholipid:palmitic acid:triglyceride was approximately $1: 4: 45$ in lipid extracts from the lung homogenates at 5 h. About $1 \%$ of the label from tripalmitin was recovered in SPC at each time point. There were negligible amounts of tripalmitin derived label in the liver and the plasma.

\section{DISCUSSION}

To appreciate the findings regarding the metabolism of these neutral lipids, one must consider how palmitate and tripalmitin came to comprise such significant proportions of surfactant mixtures used both clinically and in reconstruction experiments with the surfactant specific proteins (5, 9-11). In 1980, Fujiwara et al. (6) reported the successful treatment of severe RDS in 10 infants with artificially modified natural surfactant (22). Since then, numerous clinical trials have reported the efficacy of various forms of natural and artificial surfactant. These different formulas have been designed to mimic the in vitro surface properties of natural surfactant, which are thought to be critical to its in vivo action $(23,24)$. These properties, as determined with the Willhemy balance or the oscillating bubble, include adsorption to the surface of a liquid interphase, spreading to achieve an equilibrium surface tension of $25-35$ dyne $/ \mathrm{cm}$ in less than $1 \mathrm{~min}$, establishment of the equilibrium surface tension, and lowering the equilibrium surface tension to less than 20 dyne $/ \mathrm{cm}$ with a small compression of the surface area with reproducible changes over multiple compression and expansion cycles (25). With these criteria in mind, the original organic solvent extracted surfactant of Fujiwara et al. (6) was modified to yield a suspension that possessed excellent surface properties: rapid spreading, rapid adsorption, minimum surface tension less than 10 dynes $/ \mathrm{cm}$, a reproducible surface tension-area diagram

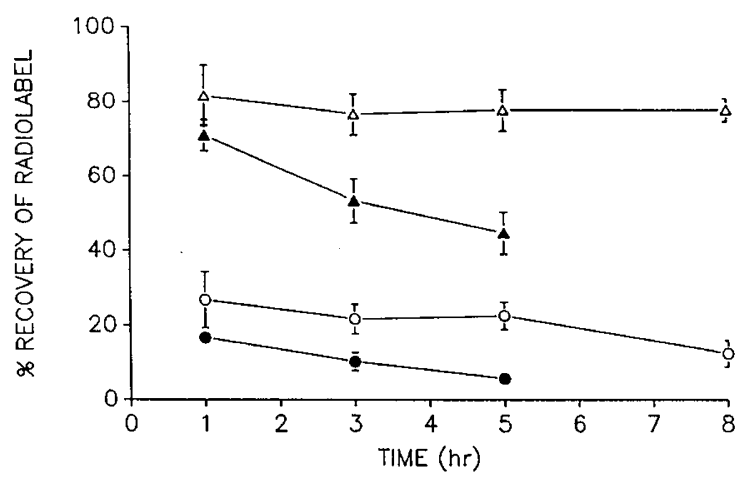

Fig. 4. Recovery of surfactant-associated labeled tripalmitin given by intratracheal injection to 132-d sheep. Error bars not shown fall within the symbols. The recovery of $\left[{ }^{14} \mathrm{C}\right]$ tripalmitin in the lipid extracts are given for the alveolar wash in trace $(\bullet)$ and treatment $(O)$ doses of surfactant and the total lung in trace $(\boldsymbol{\Lambda})$ and treatment $(\Delta)$ doses of surfactant. The recovery in both the alveolar wash and the total lung was significantly greater for the treatment dose at 3 and $5 \mathrm{~h}(p<0.05)$. 
with a maximum surface tension of 27-30 dynes/cm, and a very low surface compressibility. The final formula, survanta, contained by wt $47 \%$ DPPC, $7 \%$ palmitic acid, $7 \%$ tripalmitin, $2-$ $3 \%$ proteins (primarily the low molecular wt surfactant proteins $\mathrm{B}$ and $\mathrm{C}$, and not the larger surfactant protein $\mathrm{A}$, which is removed by the lipid extraction process), and other phospholipids and neutral lipids (5). A 10-20\% combined concentration of fatty acids and triglycerides was essential for the observed surface properties, particulary spreading and lowering the surface tension during the compression-expansion cycles. Palmitic acid and tripalmitin were chosen as the fatty acid and triglyceride respectively because they were the most abundant in natural surfactant. As individual components, palmitic acid possessed better surface properties than tripalmitin, but the preparation containing both demonstrated the best activity (9).

Tanaka et al. (23) demonstrated that this preparation, which had good surface properties in vitro, restored normal pressurevol characteristics to the excised lavaged rat lung and to premature rabbit lungs. Further clinical studies demonstrated the efficacy of survanta in treating RDS in humans (6-8). The assumption was that the in vitro surface properties this preparation possessed, properties that were dependent on significant concentrations of palmitic acid and tripalmitin, were critical to the experimental and clinical results. Our findings raise considerable doubt concerning the accuracy of this assumption.

These studies show that palmitic acid in surfactant will be cleared rapidly from the airspaces of adult and premature rabbits and premature sheep, regardless of whether given with trace or treatment doses of surfactant. This clearance is much more rapid than that of the phospholipids or cholesterol found in similar doses of surfactant $(13,14)$. The marked contrast between palmitate and DPPC was evident in the adult rabbit, where the recovery ratio of DPPC:palmitic acid from the alveolar wash at $30 \mathrm{~min}$ was $40: 1$ and over $100: 1$ by $2 \mathrm{~h}$. Although the clearance of tripalmitin is much slower than that of palmitic acid, the relative concentrations of DPPC:tripalmitin:palmitic acid are soon drastically altered. Approximately $25 \%$ of intratracheally administered DPPC can be recovered from the alveolar wash of the preterm sheep at $5 \mathrm{~h}$, and approximately $20 \%$ at $24 \mathrm{~h} \mathrm{(15).}$ Using these estimations, the recovery ratio of DPPC: tripalmitin:palmitic acid from the alveolar wash is approximately $350: 50: 1$ at $5 \mathrm{~h}$ and $300: 25: 1$ at $8 \mathrm{~h}$ in 132-d lambs receiving treatment doses of survanta, decidedly different from the $7: 1: 1$ ratio found in the original suspension. Survanta has been shown in clinical trials and in preterm lambs to improve oxygenation and decrease mean airway pressure for periods up to $24 \mathrm{~h}$ after administration $(8,15)$. Thus, the efficacy of survanta persists long after the palmitic acid is cleared from the lung. This is not altogether surprising, because surfactant suspensions of organic solvent extracts of calf lung alveolar washes that do not contain palmitic acid or triplamitin have been shown to be effective in vivo as well as clinically $(26,27)$.

These findings illustrate the difficulties in determining what makes a good surfactant. The surface active properties of natural surfactant and organic solvent extracted surfactants have been characterized. The basic assumption is that these properties are responsible for the clinical function of natural surfactant. Therefore, any artificial or modified surfactant to be used clinically must possess these surface properties. The flaw in this logic is that there is no definitive proof of the relative importance of the various in vitro surface properties of surfactant to in vivo function. This should be kept in mind as new surfactant formulas and preparations are devised and tested for the treatment of RDS.

Although tripalmitin was not metabolized to a remarkable degree in the preterm lamb lung, the fate of palmitic acid was strikingly different. Large quantities of palmitate were cleared from the airspaces and lung tissues of animals given treatment doses of surfactant. Preterm lambs at $132 \mathrm{~d}$ gestational age and preterm rabbits at $28 \mathrm{~d}$ gestational age have surfactant pool sizes recoverable by alveolar wash of about 1-2 mg total surfactant lipid/ $\mathrm{kg}(15,18,28)$. Assuming their surfactant contained $1 \%$ palmitic acid, these animals would have only 10-20 $\mu \mathrm{g}$ palmitic $\mathrm{acid} / \mathrm{kg}$ in the alveolar surfactant pool. The treatment dose delivered about $7 \mathrm{mg} / \mathrm{kg}$ palmitic acid, in excess of a 500 -fold increase of the endogenous pool.

Although most of the labeled palmitic acid disappeared from the lung, a portion was used as a substrate for the formation of phospholipids. By 2-3 h, less than $5 \%$ of the isotope was recovered from the total lung as palmitic acid in any of the animal models. At this time, approximately $15 \%$ was recovered from the total lung as phospholipids in the immature rabbit, and roughly the same in the adult rabbit (10\% as SPC). A smaller proportion was found in phospholipid in the immature sheep. At $3-8 \mathrm{~h}$, about $5 \%$ of the isotope from the treatment dose was recovered as phospholipid. A small amount was converted to tripalmitin in the lamb lung but only negligible amounts of labeled tripalmitin were found in the rabbit lungs of preterm lambs. The remainder of the palmitic acid presumably was used as an energy source or left the lung rapidly to become incorporated into lipids in other organs such as the liver (29).

In summary, palmitic acid was cleared rapidly from the airway to the lung, and most of the labeled palmitic acid was lost rapidly from the lung in both adult and preterm animals. A sizable proportion of tripalmitin remained in the airways, with the majority of the remainder remaining in the lung. Palmitic acid should not be expected to play a major role in the function of surfactant other than perhaps facilitating initial spreading of the surfactant before the palmitate is cleared from the lungs. Some of the palmitic acid was used as a substrate for lung lipid synthesis. The possible importance of alveolar palmitate as a substrate has not been evaluated, although alveolar palmitate was more efficiently used for surfactant synthesis than was intravascular palmitate (12). The lung appears to have the potential to synthesize much of the palmitate required for surfactant synthesis $(30,31)$; however, supplemental palmitate could be beneficial to the preterm lung. Although we found no detrimental effects resulting from the presence of palmitate or tripalmitin in surfactant, their importance to surfactant in vivo can be interpreted only with an understanding of their metabolic fates.

\section{REFERENCES}

1. King RJ, Clements JA 1972 Surface active materials from dog lung II. Composition and physiological correlations. Am J Physiol 223:715-726

2. VanGolde LMG 1976 Metabolism of phospholipids in the lung. Am Rev Respir Dis 114:977-1000

3. Ohno K, Akino T, Fujiwara T 1978 Phospholipid metabolism. In: Scarpelli EM, Cosmi EV. (eds) Reviews in Perinatal Medicine, Vol 2. Raven Press, New York, pp 227-318

4. Yu S, Harding PGR, Smith N, Possmayer F 1983 Bovine pulmonary surfactant. Lipids 18:522-529

5. Fujiwara T 1984 Surfactant replacement in neonatal RDS. In: VanGold LMG, Batenburg JJ (eds) Pulmonary Surfactant. Elsevier Science Publishers, Amsterdam, pp 479-503

6. Fujiwara T, Chida S, Watabe Y, Maeta H, Morita T, Abe T 1980 Artificial surfactant therapy in hyaline-membrane disease. Lancet 1:55-59

7. Gitlin JD, SoIl RF, Parad RB, Hobar JD, Feldman HA, Lucey JF, Taeusch HW 1987 Randomized controlled trial of exogenous surfactant for the treatment of hyaline membrane disease. Pediatrics 79:31-37

8. Hobar JD, Soll RF, Sutherland J, Kotagal U, Philip AGS, Kessler DL, Little G, Edwards W, Vidyasager D, Raju TNK, Jobe AH, Ikegami M, Mullett MD, Myerberg DZ, McAuliff TL, Lucey JF 1989 A multicenter randomized controlled trial of single dose surfactant therapy for respiratory distress syndrome. N Engl $J$ Med 320:959-965

9. Tanaka Y, Takei T, Kanazawa Y 1983 Lung surfactants II. Effects of fatty acids, triacylglycerols and protein on the activity of lung surfactant. Chem Pharm Bull 31:4100-4109

10. Nohara K, Berggren P, Curstedt T, Grossman G, Nilsson R, Robertson B 1986 Correlations between physical and physiological properties of various preparations of lung surfactant. Eur $\mathcal{J}$ Respir Dis 69:321-335

11. Tanaka Y, Takei T, Aiba T, Masuda K, Kiuchi A, Fujiwara T 1986 Development of synthetic lung surfactants. J Lipid Res 27:475-485

12. Jacobs H, Jobe A, Ikegami M, Jones S, Miller D 1983 Route of incorporation of alveolar palmitate and choline into surfactant phosphatidylcholine in rabbits. Biochim Biophys Acta 752:178-181 
13. Pettenazzo A, Ikegami M, Seidner S, Jobe A 1988 Clearance of surfactant phosphatidylcholine from adult rabbit lungs. J Appl Physiol 64:120-127

14. Pettenazzo A, Jobe A, Ikegami M, Abra R, Hogue E, Mihalko P 1989 Clearance of phosphatidylcholine and cholesterol from liposomes, liposomes loaded with metaproterenol, and rabbit surfactant from adult rabbit lungs. Am Rev Respir Dis 139:752-758

15. Ikegami M, Jobe A, Yamada T, Priestley A, Ruffini L, Rider E, Seidner S 1989 Surfactant metabolism in surfactant treated preterm ventilated lambs. J Appl Physiol 67:429-437

16. Taeusch HW, Keough KMW, Williams M, Slavin R, Steele E, Lee AS, Phelphs D, Kariel N, Floros J, Avery ME 1986 Characterization of bovine surfactant for infants with respiratory distress syndrome. Pediatrics 77:572-581

17. Ikegami M, Berry D, Elkady T, Pettenazzo A, Seidner S, Jobe A 1987 Corticosteroids and surfactant change lung function and protein leaks in the lungs of ventilated premature rabbits. J Clin Invest 79:1371-1378

18. Seidner S, Jobe AH, Ruffini L, Ikegami M, Pettenazzo A 1989 Recovery of treatment doses of surfactants from the lungs and vascular compartments of mechanically ventilated premature rabbits. Pediatr Res 25:423-428

19. Ikegami M, Agata Y, Elkady T, Hallman M, Berry D, Jobe A 1987 Comparison of four surfactants: in vitro surface properties and responses of preterm lambs to treatment at birth. Pedatrics 79:38-46

20. Bligh EG, Dyer WJ 1959 A rapid method of total lipid extraction and purification. Can J Biochem Physiol 37:911-917

21. Mason RJ, Nellenbogen J, Clements JA 1976 Isolation of disaturated phosphatidylcholine with osmium tetroxide. J Lipid Res 17:281-284
22. Jobe A, Ikegami M 1976 Surfactant for the treatment of respiratory distress syndrome. Am Rev Respir Dis 136:1256-1275

23. Tanaka Y, Kakei T, Masuda K 1983 Lung surfactants III. Correlations among activities in vitro in situ and in vivo, and chemical composition. Chem Pharm activities in vitro in

24. VanGolde LMG, Batenburg JJ, Robertson B 1988 The pulmonary surfactan system: biochemical aspects and functional significance. Physiol Rev $68 \cdot 374$ 455

25. Notter RH 1984 Surface chemistry of pulmonary surfactant: the role of individual components. In: Robertson B, VanGold LMG, Batenburg JJ (eds) Pulmonary Surfactant. Elsevier Science Publishers, Amsterdam, pp 17-65

26. Notter RH, Egan EA, Kwong MS, Holm BA, Shapiro DL 1985 Lung surfactan replacement in premature lambs with extraced lipids from bovine lung lavage: effects of dose, dispersion technique, and gestational age. Pediatr Res 19: 569-577

27. Enhorning G, Shennan A, Possmayer F, Dunn M, Chen CF, Milligan J 1985 Prevention of neonatal respiratory distress syndrome by tracheal instillation of surfactant: a randomized clinical trial. Pediatrics 76:145-153

28. Ikegami M,. Jobe A, Yamada T, Seidner S 1989 Relationship between alveolar saturated phosphatidylcholine pool sizes and compliance of preterm rabbit lungs. Am Rev Respir Dis 139:367-369

29. Stantcheva IG, Post M, Batenburg JJ, VanGold LMG 1982 Metabolic fate of fatty acids in type II cells isolated from adult rat lung. Lung 160:267-273

30. Maniscalco WM, Finkelstein JN, Parkhurst AB 1983 De novo fatty acid synthesis by freshly isolated alveolar type II epithelial cells. Biochim Biophys Acta 751:462-469

31. Maniscalco WM, Finkelstein JN, Parkhurst AB 1983 De novo fatty acid synthesis in developing rat lung. Biochim Biophys Acta 711:49-58 